\title{
A CONSTRUÇÃO DE UMA ELITE LOCAL NA SEGUNDA METADE DO SÉCULO XIX: O PERCURSO DA FAMÍlLIA LEITÃ̃, EM LEIRIA
}

\begin{abstract}
Ao traçar a história de vida de uma família, não se obedece ao princípio de que o acontecimento, só por si, não tem significado histórico. $O$ encontro de detalhes da existência dos individuos escolhidos torna-se um momento de conquista para o estudioso. Foram cruzados diversos tipos de fontes, tornando mais fiaveis alguns dos dados fornecidos, por exemplo, através da imprensa local. Para esta fase do trabalho sobre a família Leitão, foi trabalhada, essencialmente, informação qualitativa. Determinou-se, como meta inicial, estabelecer o perfil do homem responsável por cada acto que era dado a conhecer. $O$ passo seguinte foi compreender a coerência global do grupo familiar. $O$ percurso da família Leitão permitiu a construção de um olhar sobre a formação e os limites de intervenção de uma elite, a nivel local.
\end{abstract}

Alda Mourão Filipe*

\section{OS PROBLEMAS METODOLÓGICOS}

O estudo do empresariado do século XIX revela personalidades de origem diversa, cujas "histórias de vida" foram o resultado da procura de estratégias de sucesso. A reconstituição biográfica de algumas personagens mais destacadas na vida económica permite traçar o perfil da conduta empresarial de um grupo que liderou a elite local.

* Professora Adjunta do Departamento de Ciências Sociais - Escola Superior de Educação, Instituto Politécnico de Leiria. Doutoranda em História Contemporânea, na Faculdade de Letras da Universidade de Coimbra. 
Origem, trajectórias sociais, estilos de vida, redes de sociabilidade horizontais e transversais, laços de família, educação, experiência e formação empresarial, intervenção na política local são alguns dos tópicos a considerar. A eles adicionamos a intervenção cultural.

Também o estudo de percursos individuais e familiares, a que procedemos, demonstrou a convergência para "um grupo com forte identidade e coesão social, que passou pela adopção de um estilo de vida similar, pelo estreitar de laços de parentesco e pela partilha do protagonismo na aç̧ão política"l.

Acompanhar o percurso de vida de uma família, e os atalhos abertos pelos seus membros, coloca desafios e limitações ao trabalho do investigador. As dificuldades são particularmente sentidas no campo da História, ao pôr ao seu serviço uma metodologia largamente utilizada (mas, simultaneamente, posta em causa) por outras disciplinas da área do social. A própria Sociologia reabilitou a "história de vida", concedendo-lhe um estatuto científico por permitir leituras sobre uma sociedade, através de múltiplas histórias singulares $^{2}$. De facto, a abordagem do objecto de estudo oscila entre o individual e $o$ interindividual, entre $o$ acontecimento e a sociedade que $o$ contextualiza. A procura de fontes, o cruzamento e a validação de dados trazem para um primeiro plano a vida quotidiana de um tempo médio e de um espaço restrito. A banalidade do dia-a-dia assume dimensão histórica e sociológica, depois de ultrapassada uma fase inicial que tivera contornos muito próximos dos da literatura.

Ao esboçar a história de vida de uma família, contraria-se o princípio, tão grato a autores de outros estudos, de que o acontecimento, só por si, não tem significado histórico. $\mathrm{O}$ encontro de detalhes da existência dos indivíduos que focalizamos torna-se um momento de conquista para o estudioso. São os factos, mesmo insignificantes, que nos aproximam de uma realidade muito concreta. $\mathrm{O}$ indivíduo vai-se revelando. Passamos, através dele, à família. Atingimos práticas singulares da vivência quotidiana que nos conduzem ao grupo social, nas suas múltiplas manifestações.

O investigador acabará por utilizar todas estas pequenas peças para se familiarizar com a situação em estudo. Os ganhos informativos são muito significativos, no que respeita à profundidade da análise permitida. Mas as perdas sentidas, quanto à impossibilidade em elaborar estatísticas representativas ou em generalizar as conclusões alcançadas são, igualmente, muito importantes. Nunca o poderemos esquecer. Passa a ter-se a imagem clara dos indivíduos, apesar da sua ausência física.

Como procedemos, sob o ponto de vista metodológico? Percorremos fontes diversas que passaram pelos registos paroquiais e notariais, pela imprensa local, pelos arquivos de organismos oficiais. Esgotámos as fontes ao nosso alcance, para cobrir o máximo da existência de quem nos interessava, no 
sentido de ir ao encontro da coerência integral do conjunto. Não isolámos nenhum elemento da família em estudo, para não perder o retrato global do grupo.

Cruzámos os diversos tipos de fontes, o que assegurou não só um conhecimento mais alargado da realidade em estudo, como também a fiabilidade de alguns dos dados fornecidos, por exemplo, através da imprensa. Para esta fase do trabalho sobre a família Leitão, trabalhámos, essencialmente, informação qualitativa ${ }^{3}$. Propusemos, como meta inicial, estabelecer o perfil do homem responsável por cada acto que íamos conhecendo. $\mathrm{O}$ passo seguinte foi compreender a coerência global do grupo familiar. Acompanhámo-lo, enquanto sujeito interveniente na vida económica, social, cultural, política da sua cidade. Esforçámo-nos para, através desta metodologia, chegar a resultados que não tivessem qualquer cunho da familiaridade entre investigador e investigados, de acordo com as exigências da crítica histórica a que estamos sujeitos.

\section{UMA FAMÍLIA DE COMERCIANTES}

No início da década de 1850, a família Leitão começava a marcar uma forte presença no comércio da cidade de Leiria.

O pai, Luís Joaquim Leitão, ao falecer, em 3 de Novembro de $1850^{4}$, legara à mulher e aos filhos, ainda não estabelecidos por sua conta, um estabelecimento sito nas lojas da sua residência, na Praça Rodrigues Lobo, a zona nobre da cidade. As três filhas que consigo residiam, uma viúva e as outras solteiras, passaram a colaborar com a mãe. Entregaram a escrituração comercial ao irmão Paulino que, ao estabelecer a sua própria loja, foi substituído por José.

Em Março de 1853 morre a mãe, D. Rita de Cacia Leitão. Deixava oito filhos, todos maiores. No final desse ano, a família reuniu-se em casa do irmão mais velho, Miguel, também já com loja aberta na cidade. Era necessário proceder à partilha dos bens ${ }^{5}$. Para tal, o notário abria uma excepção à prática da sua actividade, só concedida a um número restrito de pessoas: deslocava-se à residência dos clientes. Os bens a dividir eram avaliados em $2744 \$ 201$ réis e incluíam mobiliário, uma dívida do irmão Paulino, uma casa de habitação e três propriedades na periferia urbana. A mãe manifestara a vontade, como última disposição, de a loja que explorava, sob a designação de firma Viúva Leitão \& Filhos, ficar para Maria da Nazaré, Carolina, Guilhermina e José. O sentido da protecção maternal foi prolongado pelos irmãos que, entre si, combinaram atribuir a casa de habitação às irmãs residentes em Leiria. Paulino colocava uma condição: que aquelas the mantivessem o arrendamento 
de uma das lojas do prédio, que ele já ocupava ${ }^{6}$. A família Leitão explorava, assim, três casas comerciais na Praça da cidade: a de Paulino, a de Miguel e a que fora dos pais, mas explorada, na altura, por quatro irmãos, sob a liderança de José. No final, cada um recebeu $121 \$ 707$ réis em dinheiro. No acesso aos bens, ficaram de fora $D$. Júlia, casada com um tenente de cavalaria, e Miguel Joaquim Leitão, eventualmente por apresentarem uma estabilidade económica distinta da dos seus irmãos.

José Joaquim Leitão prolongava uma experiência herdada dos pais. Formou, então, uma sociedade com as irmãs, para dar continuidade à loja "de mercadoria e capela que ficou por morte da mãe, D. Rita de Cacia Leitão"? Fundava-se, pela primeira vez, a firma Leitão \& Companhia. A linha masculina vai-se destacar, acabando as mulheres por se afastarem, por casamento ou pelo lugar de sombra a que serão remetidas.

José, Paulino e Miguel Joaquim Leitão encabeçavam estabelecimentos na zona comercial, isto é, na Praça Rodrigues Lobo e nas ruas que a circundavam. Dos três, Miguel era, sem dúvida, o que já alcançara posição cimeira, pois, em 1852, o seu nome integrava a lista dos " 40 maiores do concelho", elaborada pela Câmara Municipal, em função do valor colectado sobre o imposto da décima ${ }^{8}$.

\section{A PRIMEIRA GERAÇÃO}

\subsection{Miguel Joaquim Leitão: o patriarca}

\subsubsection{O prestígio cimentado pela actividade económica}

Ao longo de mais de trinta anos, o nome de Miguel Joaquim Leitão foi sendo enriquecido com atributos adquiridos, principalmente, pela via económica. Assim a qualificação de "negociante de grosso trato nesta cidade", como foi por mais de uma vez identificado por notários de Leiria, significava o duplo reconhecimento do seu valor pessoal. Por um lado, foi-o pelo homem de leis, habituado à composição de textos estandardizados, repetitivos. Por outro lado, foi-o pelo comerciante local, companheiro de classe que hierarquiza os seus iguais e respeita os mais importantes.

A configuração da sua fortuna fez-se através de estabelecimentos que liderou, como único proprietário ou como sócio maioritário. Esteve presente nos números iniciais do primeiro jornal publicado na cidade de Leiria, $O$ Leiriense. Corria o ano de $1854 \mathrm{e}$, repetidamente, eram publicitados artigos que se podiam encontrar à venda na loja do Sr. Miguel Joaquim Leitão. 
O estabelecimento sobressaía pela frequência de alusões. Destacava-se, também, pela diversidade de artigos que oferecia.

A apresentação dos armazéns de Miguel Leitão fez-se em Julho, já o jornal ia no número sete. Dois anúncios distintos publicitavam produtos bem diversos. No centro da página quatro, sob o desenho de uma garrafa, o leitor era envolvido pela promessa de poder encontrar "vinhos ingarrafados", entre os quais destacava Champagne, Madeira, Porto, Muscatel, Lavradio, Bastardinho, Bairrada, Saborosa e Torres Novas ${ }^{10}$. O resto da colheita de tinto, de qualidade especial, estava ainda disponível, ao preço de 80 réis, por garrafa. Nessa mesma página, mas um pouco mais abaixo e completamente ajustado à esquerda, dava-se conta de outro segmento de artigos disponíveis: 0 das fazendas e da retrosaria. Assim, para corresponder a uma maior variedade de gostos e de posses, tinha nas suas prateleiras fazendas nacionais e estrangeiras, entre as quais destacava os panos crus, os cetins, as bombazines. Além de tudo isto, ainda tinha à disposição do público papel, papelão, papéis pintados, avisos para o imposto da décima e das contribuições indirectas.

A primeira imagem que nos proporcionou foi a de um grande espaço comercial que, acompanhando as características do comércio de meados do século XIX, não manifestava qualquer especialização. Pelo contrário, os dois primeiros anos de vida do periódico confirmaram, e até reforçaram, esta constatação.

No final do ano de 1854 , já em pleno Inverno, dirigia-se à vaidade, quer feminina, quer masculina. Tinha grande variedade de "fazendas de lã de bons gostos, próprias para a estação invernosa, tanto em casemiras de côr, como em montanhaks, meltons, retinas, estrekan, pano de foca" ${ }^{11}$. Apesar de acenar com "preços cómodos", dirigia-se, sem dúvida, a uma restrita camada citadina, no que respeita a gostos, a hábitos e a bolsas.

O balanço a fazer deste prévio conhecimento da loja e armazém de Miguel Joaquim Leitão saldava-se pela grande dimensão comercial que manifestava, relativamente à concorrência movida pelos outros comerciantes. Até a oportunidade em se fornecer dos produtos mais adequados e diversos, em função do calendário, prognosticava o cimentar de um lugar de primeiro plano, que iria viver por algumas décadas.

Acabávamos de conhecer quem já era um grande comerciante da praça leiriense. Os anos seguintes iriam confirmá-lo. Mais ainda: Miguel Joaquim Leitão viria a demonstrar capacidades próprias de quem gera riqueza, através da criatividade, da adaptabilidade e do investimento. Era um empresário dos tempos modernos, apesar do peso do provincianismo e da tradição.

Continuou a alargar a quantidade e a variedade dos stocks. Captou um sector de público muito restrito, quando passou a vender uma obra fundamental para o conhecimento do Distrito de Leiria, mas que a poucos 
interessava. Tratava-se da Estatistica do Districto de Leiria, "de D. António da Costa de Sousa Macedo, secretário-geral do distrito. Obra pioneira no nosso país, que se rege pelos métodos dos principais estatísticos da Europa, depois do Congresso Estatístico de Bruxelas, em 1853"'2 . O livro acabara de ser impresso, sendo de toda actualidade a informação que transmitia. Para cativar o público leitor, em Maio, o anúncio ocupava toda a página quatro. Vai manter-se até finais de Setembro, reduzindo a mancha ocupada para metade.

O mercado leiriense não conhecia ainda nenhuma livraria, mas o sucesso alcançado com a venda da Estatistica do Districto de Leiria motivou Miguel Joaquim Leitão a continuar a apostar neste tipo de produto. A esta atitude não era estranho o facto de assumir o cargo de director da Tipografia Leiriense, responsável pela impressão, não só da obra referida, como também do próprio jornal. Da mesma forma que, à forte presença publicitária, não era indiferente a relação que o empresário tinha com $O$ Leiriense, assumindo o cargo de administrador do periódico entre Outubro e Dezembro de 1855 (CABRAL, 1975: 261). Através de um anúncio de média dimensão, a partir de 6 de Outubro de 1855, passou a dar a conhecer o que o público leitor, ávido de saberes, podia encontrar na Loja Leitão. Tratava-se da Revista Peninsular, "colaborada por escritores portugueses e ispanhois. É impressa promiscuamente nas duas linguas. Cada número de 32 páginas terá ordinariamente um retrato" ${ }^{13}$. Podia adquirir-se avulso ou fazendo assinatura.

Miguel Joaquim Leitão, através do seu estabelecimento, protagonizava o querer criar condições para enriquecer o fraco panorama cultural de Leiria. Reforçámos esta opinião, quando assistimos ao seu envolvimento em actividades teatrais e recreativas na cidade.

Mas a grande versatilidade empresarial de Miguel Joaquim Leitão foi demonstrada com a implantação de carreiras regulares, que efectuavam o percurso entre Leiria e a Vala do Carregado. A comodidade dos passageiros estava prevista com a saída de Leiria, no Verão, às 22 horas "a fim de passar o calor do dia seguinte nas Caldas da Rainha. Em a noite de $4^{a}$. feira seguirá viagem athe à vala do Carregado, onde espera pelo vapor de condução a Lisboa" ${ }^{14}$. Eram estipulados os preços quer de passageiros, quer de mercadorias. No ano anterior, a Administração Geral dos Correios abrira um concurso para serviço diário de carruagens, para circular entre o Carregado e Coimbra $^{15}$. O resultado da experiência oficial, que desconhecemos, não agradou aos viajantes ou, pelo contrário, não foi suficiente para a procura. Seja qual for a razão, o certo é que Miguel Joaquim Leitão vai criar uma alternativa ao serviço público, ampliando a oferta proporcionada pela sua empresa. Em Dezembro desse ano, perante dúvidas que se haviam levantado, quanto aos preços praticados, era repetida a publicação da lista. Acrescentava-se em nota: "O creado é sustentado à custa do passageiro ou passageiros" ${ }^{16}$. A 
familiaridade do serviço era notável. Da prática, conhecida nos meses anteriores, clarificou-se o preço estipulado para os objectos mais frequentemente transportados: cadeiras, 180 réis, lavatórios, 240 réis, leitos de ferro, 500 réis, e chapeleiras, 400 réis. As pessoas faziam deslocar, principalmente, peças de mobiliário indispensáveis à fixação de um novo alojamento em Leiria ou em Lisboa.

A mercadoria com que se fornecia a Casa Leitão, e de cujo transporte era responsável, vinha principalmente de Lisboa. Utilizava diligências. Trazia fazendas, nacionais e estrangeiras. O empacotamento era feito de modo a que a mercadoria chegasse ao destino no melhor estado possível. Para isso, eram utilizados baús, naturalmente grosseiros, que evitavam a exposição às agressões naturais, aos extravios e à deterioração. Recebidos os artigos em Leiria, o estabelecimento passava a "vender baus de 3,5 palmos, 4 e 4,5 pelo que lhe custaram em Lisboa e que só serviram para conduzir as fazendas para o armazém"17.

Enquanto único responsável pela política empresarial imposta, optou por criar um sistema comercial tentacular. Isto é, angariou pequenos comerciantes que, como seus agentes, se deslocavam entre mercados e feiras da região. Através do comércio ambulante, criava um meio de se tornar presente perante um público afastado geograficamente da cidade, culturalmente dos hábitos urbanos, psicologicamente do acesso à melhor loja de Leiria ${ }^{18}$. Alargava os seus lucros, à custa da conquista de novos mercados, que diversificava, igualmente, aproveitando oportunidades conjunturais. Assim, quando estacionaram tropas em Leiria, criou uma sociedade que fornecia "rações a seco de pão e forragens" 19 . O ganho estava garantido e Miguel Joaquim Leitão era o verdadeiro sócio capitalista, que recebia uma pequena maquia de um seu parceiro social e transferia a administração do fornecimento para um terceiro.

Atento às carências comerciais de um ou outro concelho vizinho, substituiu-se à iniciativa dos locais, abrindo sucursais. A primeira a ser inaugurada foi a de Vila Nova de Ourém, que contava com um armazém de artigos análogos aos que vendia em Leiria ${ }^{20}$. Seguir-se-ão os depósitos de tabaco em Porto de Mós e Vieira ${ }^{21}$. A ligação à Companhia Nacional dos Tabacos, como sabemos, obrigava a uma fiança que cobrisse todos os riscos, o que, só por si, já criava uma selecção de colaboradores ${ }^{22}$.

Para além destas atitudes, no panorama regional, promovia actos de acumulação de riqueza, bastante tradicionais. Emprestava dinheiro, a troco do pagamento de um juro e da segurança de uma hipoteca. Até 1873, acompanhamos esta actividade ligada ao crédito, que culminou, exactamente nesse ano, com um empréstimo de $750 \$ 000$ réis, concedido a uma irmã, D. Carolina Porfírio Leitão Crespo, e ao cunhado ${ }^{23}$. Até lá, os montantes 
envolvidos eram mais modestos, tal como o eram os devedores: pequenos comerciantes, maioritariamente.

De alguma forma, pode antever-se, através das relações que se iam estruturando, uma liderança conseguida, também, pelo crédito. Era óbvio que assim fosse. Afinal, o espaço em que nos movimentamos é o espaço económico, que conduz a aquisições na esfera do social.

Fez um percurso comum a grande parte de pequenos e grandes capitalistas do século XIX: tornou-se também proprietário. Social, económica e culturalmente era uma personalidade aberta aos novos gostos, que apresentavam o "ir a banhos" como benéfico para a saúde e como forma de afirmação de poder. Era, então, senhor de uma segunda residência de férias, em S. Pedro de $\mathrm{Muel}^{24}$. O seu património imobiliário compreendia a morada de casas de dois andares, onde residia e estabelecera a sua loja, no centro da cidade de Leiria, na Rua do Açougue, mais tarde apelidada de Rua do Comércio; uma outra casa na Rua da Amoreira, também naquela cidade. Em $S$. Pedro de Muel, para além da que já referimos, possuía uma outra mais pequena. $\mathrm{O}$ mesmo se verificava em Monte Redondo ${ }^{25}$. As suas propriedades distribuíam-se também pela Marinha Grande e pelo vizinho concelho de Vila Nova de Ourém. Aqui comprou, de uma só vez, trinta propriedades ${ }^{26}$. A idade, também o facto de ter ficado viúvo, em 1877 , bem como uma situação económica menos desafogada levaram-no a desfazer-se destes últimos bens ${ }^{27}$. Manterá o usufruto das casas, pois haviam sido atribuídas à filha mais velha, por vontade expressa em testamento pela mulher ${ }^{28}$.

São desconhecidos os motivos que o levaram, em 1860, a contrair um empréstimo de dois contos de réis. Tudo ficou na família, pois seria o irmão Paulino a adiantar o montante ${ }^{29}$. Levará quatro anos a amealhar tão alto valor, formalizando-se a quitaçã̀o da dívida em $1864^{30}$. Gente habituada a lides do mundo do capital, não usaram o foro privado, familiar, para tomar decisões sobre este empréstimo. $O$ parentesco não ultrapassou o acto público, a presença do notário. Mas foi uma fase transitória na vida deste comerciante.

\subsubsection{A intervenção na vida cultural e o prestígio social}

O estabelecimento de Miguel Joaquim Leitão, para além da função económica, era centro de encontro de leirienses interessados em abrir a cidade a experiências que a tirassem do marasmo provinciano. A porta aberta para os clientes servia também para criar laços de interesses, cumplicidades e companheirismo. A loja era um espaço de convívio social, onde se discutia e decidia sobre o que podia alterar as rotinas, enriquecendo o espírito, alimentando o lazer. Logo em 1851, um grupo de leirienses formou uma 
sociedade com o fim de "se construir n'esta cidade uma praça de touros ... para se fazerem corridas pela occasião da festa do Espirito Santo e as mais vezes que entenderem" ${ }^{\prime 31}$. Entre os sócios contava-se com a presença de Miguel Joaquim Leitão. A praça situava-se no centro da cidade, junto ao rio, na zona conhecida como Rossio. Vinha dar continuidade a uma tradição recreativa que os leirienses apreciavam, como forma de enriquecer festividades do calendário religioso. A precariedade das instalações, feitas em madeira, limitava bastante a sua longevidade, acabando por ser rapidamente demolidas. Este grupo apostava numa duração mais prolongada, só possível através da qualidade da construção. Sabemos que não concretizaram plenamente os seus objectivos, pois, em reunião camarária de 18 de Julho de 1859 (CABRAL, 1975: 418-419), foi intimado o construtor a demolir a praça de touros que havia erguido.

Esta personalidade revelara, desde cedo, uma afeição muito particular pelo teatro. Desconhece-se a origem da formação deste seu gosto. Admitimos ter-se tratado de um autodidacta. Em 1854 era secretário da Comissão do Teatro de S. Pedro, único organismo cultural da cidade que se dedicava à arte dramática $^{32}$. Neste espaço, para além de representações levadas à cena por "curiosos" locais, tinham lugar as principais festas que Leiria conhecia. Períodos, como o Carnaval, levaram a alterar a programação, pois o Teatro tornava-se lugar de bailes e festejos, onde as famílias da burguesia local se apresentavam, para proporcionar aos seus filhos uma vivência da festa com os seus iguais. Nestes momentos do calendário, havia a oferta de um espaço em que, de facto, se distinguiam os diferentes estratos da sociedade leiriense. Os filtros sociais eram impostos para qualquer tipo de espectáculo ou de festa, logo no momento da aquisição dos bilhetes. Era expressamente proibido adquirir um ingresso à porta do edifício, porque o posto de venda era na loja do Sr. Miguel Joaquim Leitão ${ }^{33}$. Ao longo de várias décadas, este estabelecimento assumiu a responsabilidade de distribuir cultura e diversão entre uma parte da população da cidade ${ }^{34}$. A sua actividade foi notável, pois, em 1907, o seu nome seria dado a um novo grupo dramático. E apresentava-se a justificação para a escolha nestes termos: "Ninguém ignora que Miguel Joaquim Leitão foi um enthusiasta do theatro e que a elle se deve o possuirmos uma bella casa de espectaculos" ${ }^{\text {"35 }}$. A notícia aludia à edificação de um espaço teatral, criado de raiz: o Teatro D. Maria Pia, inaugurado em 1880.

$\mathrm{O}$ anterior Teatro de S. Pedro mais não era do que uma adaptação feita numa velha igreja. Em 1878, Miguel Joaquim Leitão integrou uma comissão promotora da edificação, na cidade, de um Teatro e da Assembleia Leiriense. A seu lado, nesta mesma vontade, estava a nata da alta sociedade local: o Barão de Salgueiro e o Dr. António Rino Jordão (CABRAL, 1975: 393-395). Apresentaram um pedido de terreno à Câmara Municipal, na reunião de 7 de 
Janeiro de 1878. As decisões do poder foram um pouco lentas pois, apesar do reconhecido interesse, alçados e planta só foram aprovados em sessão de 29 de Julho desse ano (CABRAL, 1975: 394). Finalmente, em 17 de Outubro, era definitivamente cedido o terreno, numa das zonas mais bonitas da cidade, o Campo D. Luís I.

Dinamismo e vontade não faltaram e, daí, que a inauguração do Teatro D. Maria Pia ocorresse no dia 8 de Dezembro de 1880. A comissão promotora estava de parabéns. A Miguel Joaquim Leitão era acrescida toda a actividade desenvolvida a partir de um centro dinamizador, que fora a sua loja ${ }^{36}$. A anteceder a actividade cultural, foram criadas as estruturas necessárias à sua gestão e administração. Formalizou-se uma Associação do Teatro D. Maria Pia. Esta mantinha dois elementos do grupo que promovera a sua existência: o Barão de Salgueiro e Miguel Joaquim Leitão. O número de elementos alargou-se ao Visconde de S. Sebastião, ao advogado Dr. Afonso Xavier Lopes Vieira e ao Tenente Tomás d'Aquino Victor ${ }^{37}$. A qualidade social desta Comissão era notável. Economicamente, afiançavam o lançamento de 100 obrigações de 20000 réis cada, pela urgente necessidade em contrair um empréstimo de dois contos de réis.

A construção do seu prestígio pessoal foi sendo consolidada não só no campo económico, mas também no cultural, como temos vindo a reconhecer. A constatação, de que era personalidade de grande respeitabilidade, ressaltava de alguns actos públicos que protagonizava. $\mathrm{O}$ sucesso económico não era a única medida avaliadora do seu carácter. A forma como intervinha na vida cívica era-o também. Apresentava-se como aliado dos mais notáveis da sociedade leiriense. Casou as duas filhas com personalidades ligadas à vida judicial da região. Ambos os genros eram escrivães do Juízo de Direito: um da comarca de Leiria, outro da de Alcobaça. A actividade comercial não lhes interessou. Prolongou a casa comercial que criara, através de irmãos e sobrinhos.

\subsection{Paulino Joaquim Leitão: o primogénito}

A vocação deste membro da família Leitão, Paulino, dividiu-se entre o comércio e o funcionalismo público. $\mathrm{O}$ acumular de funções deve ter-lhe custado a denúncia de que foi alvo, em 1854, quando era Director dos Correios de Leiria $^{38}$. A crítica imediata passava pelo extravio de correspondência. Ao Subinspector-Geral dos Correios chegou mais outra acusação: a de nunca estar na estação, permitindo a ausência do seu ajudante. Recusando tais alegações, utilizava o jornal para dirigir um convite à população, para que se deslocasse aos Correios, a qualquer hora. 
Como se tratava de cargo transitório, no ano seguinte passou a identificar-se, exclusivamente, como "negociante". Viria a perder este atributo, através da pena do notário, a partir de 1904, quando passou a ser designado por "proprietário". Este era um termo demasiado vago para clarificar a nova actividade a que, então, se dedicava.

Comerciante de dimensão e visão mais limitadas do que o irmão Miguel, não deixou, esporadicamente, de utilizar as colunas de publicidade do jornal para estar mais próximo da população leitora ${ }^{39}$.

A sua vida vai evoluir de forma pouco linear, no que diz respeito à mobilização de capital. Entre 1860 e 1905 foi-lhe permitido gerir o seu dinheiro, pondo-o a render, através de empréstimos que ia concedendo, a troco de um juro que, neste longo período, nunca ultrapassou 7\%. A sua capacidade económica foi claramente demonstrada, aquando do empréstimo de dois contos de réis, que fez ao irmão Miguel. Com este fora fiador do seu outro irmão, José, da quantia de $6500 \$ 000$ réis, atestando a sua solidez economica ${ }^{40}$. Investiu no sector imobiliário, em propriedade urbana. Foi comprando casas ao redor da Praça Rodrigues Lobo que porá a render, depois de 1886. Decidiu, nesse ano, abandonar a actividade comercial, pois trespassou o seu estabelecimento de mercearia e de fazendas a um jovem caixeiro que pretendeu instalar o seu próprio negócio ${ }^{41}$. Deste contrato recebeu $1200 \$ 000$ réis, a que somou a prestação anual do arrendamento, $150 \$ 000$ réis. Que o negócio trespassado era viável, não restam dúvidas. Quando expirou este contrato, renovou-se de imediato, em 1894. Acrescentava-se mais uma loja no mesmo prédio, mas com saída para uma outra rua ${ }^{42}$. A renda baixara a $90 \$ 000$ réis. A explicação pode residir no facto de, no ano anterior, ter arrendado uma outra loja da sua casa de habitação, a um farmacêutico vindo de Peniche, por $60 \$ 000$ réis anuais ${ }^{43}$. Os contratos vigoraram até final dos anos 90, garantindo-lhe um rendimento anual não muito elevado, para o recompensar do afastamento da lide diária.

Mas a sua vida vai sofrer alterações. Em idade já avançada, acabará por contrair um empréstimo muito elevado, de dois contos, junto da firma Leitão \& Companhia. Como garantia, hipotecou a casa de dois andares, onde residia, na Praça Rodrigues Lobo. Foi avaliada em quatro contos de réis ${ }^{44}$. A vida de Paulino Joaquim Leitão não correra de forma favorável, após o seu segundo casamento. Nada o fazia prever, pois o contrato antenupcial, celebrado em 1904, registava uma fortuna estável, de ambos os nubentes. O casamento far-se-ia "com inteira separação de bens, presentes e futuros seja qual fôr o titulo da sua acquisição" "45. A noiva, D. Maria do Céu Couceiro, era solteira, natural da Marinha Grande, mas residente em Leiria. Senhora de fortuna considerável, possuía $5500 \$ 000$ réis em acções da Caixa do Crédito Predial Português, dos Bancos Lisboa e Açores, Comercial de Lisboa e Lusitano. Trazia para o 
casamento roupas, jóias e alguma mobília, totalizando $200 \$ 000$ réis. Por seu lado, o noivo contrapunha às acções as letras de que era credor, perfazendo $2718 \$ 400$ réis. Os seus bens móveis, que correspondiam ao recheio da sua residência, eram avaliados em $400 \$ 000$ réis. Qualquer um deles era proprietário de prédios de dois andares, situados em Leiria.

$O$ seu percurso de vida não teve um saldo favorável. $O$ nome e a tradição de familia permitiram-lhe o convívio com os grandes, mas foram insuficientes para permanecer no seu círculo.

\subsection{José Joaquim Leitão: o perdedor}

José Joaquim foi outro elemento da família Leitão que, para além de desenvolver actividades comerciais, esteve ligado a serviços do Estado. Começou por tomar em suas mãos o encargo de continuar com a loja que viera dos pais, como já foi referido. Apresentava-se como sócio maioritário, com uma quota de valor igual ao das suas parceiras sociais, em conjunto: 340780 réis. Senhor de $50 \%$ dos interesses no negócio, assumia as funções de administrador, a quem competia assinar toda a correspondência. Estava-lhe também entregue a "agência da loja", o que poderá significar a sua presença atrás do balcão ${ }^{46}$. Liderava a firma Leitão \& Companhia, que fora criada, com estabelecimento na Rua da Graça, próximo da Praça Rodrigues Lobo ${ }^{47}$.

Enquanto foi casado com D. Guilhermina Ribeiro da Silva Leitão, assumiu todo um conjunto de actos, conducentes ao reforço da fortuna e da estabilidade familiar. Tudo parecia correr bem, pois alargava o seu património imobiliário, comprando terrenos nas vizinhas freguesias de Pinheiros, Azóia e Marrazes ${ }^{48}$. Arrecadava também os lucros provenientes do pagamento de juros, aplicados ao capital que ia emprestando ${ }^{49}$. $\mathrm{Na}$ propriedade fundiária investia $\circ$ que ganhava no giro comercial e prestamista. Melhorava também a qualidade da sua residência. Trocou uma zona periférica da cidade, a Portela, onde tinha uma casa com quintal murado, avaliada em $576 \$ 000$ réis $^{50}$, pelo centro, a Rua do Amparo. Aqui tinha pátios, quintal e poço e valeu, em 1894, $1750 \$ 000$ réis ${ }^{51}$.

Como homem socialmente bem colocado, exibia um outro sinal exterior de riqueza: tinha uma casa de praia na Nazaré. Apesar de segunda habitação, tinha grande qualidade, pois em $1880^{52}$, foi avaliada em dois contos de réis.

As suas capacidades foram reconhecidas, ao ser nomeado Tesoureiro da Junta Geral do Distrito de Leiria, em 22 de Junho de $1869^{53}$. Exercerá este cargo por vários anos. Em 1878 aumentou o valor da caução que era obrigado a prestar. Passava-a de um para seis contos de réis ${ }^{54}$. No ano seguinte, em 
1879, ocupou o lugar de presidente da Câmara Municipal de Leiria, onde permanecerá até $1881^{55}$.

A família Leitão que, frequentemente, liderou movimentos cívicos e culturais na cidade, não tinha integrado, até então, grupos de feição política. Retirava-se do seu resguardo para entrar, na altura, nesta esfera. A sua passagem pela edilidade não foi assinalada por nenhum brilhantismo especial. Foi bastante discreta. O momento da vida de José Joaquim Leitão não era favorável a grande protagonismo. E isto porque o ano de 1880 veio revelar que o estado financeiro de José Joaquim Leitão não era estável nem equilibrado. A alteração do valor da caução poderia indiciar isso mesmo. A situação mostrava ter entrado em ruptura. As revelações iniciavam-se em Abril, quando hipotecou a casa da Nazaré a fiadores que haviam viabilizado obrigaç̃es de uma dívida, cujas causas desconhecemos. Aos irmãos Miguel e Paulino, juntavam-se o Dr. Luís Ataíde da Costa e o administrador do concelho de Leiria, José Jacinto de Matos, como fiadores ${ }^{56}$. O acto notarial, que então foi redigido, não permite destrinçar a origem que o motivou: se a pressão dos fiadores, se o reconhecimento das dificuldades vividas. $O$ que ficou registado, como razão, foi o facto de poder "acontecer que por qualquer eventualidade os primeiros outorgantes [José Joaquim Leitão e esposa] incorressem em responsabilidade para com os segundos".

A inquietação do casal Leitão não parava aqui. Algum tempo depois, em Julho, voltavam de novo ao notário, mas agora só com a presença dos irmãos, Miguel e Paulino. Afinal o passivo dos devedores era acrescido de $6500 \$ 000$ réis, valor de que aqueles eram fiadores ${ }^{57}$. Continuamos a ignorar a identidade do credor, mas, face ao montante e à necessidade que havia sido expressa aquando do reforço da caução, não é de pôr de parte a hipótese de desaire profissional.

Entretanto enviuvava e procedia a partilhas ${ }^{58}$. Pai de três filhos maiores, Luís, José e Amélia, dividiu com eles bens consideráveis. Registou imóveis e dívidas activas, que totalizaram $3760 \$ 140$ réis.

A sua meação, que ultrapassava os $1500 \$ 000$ réis, não foi suficiente para debelar compromissos anteriores. Passou a desfazer-se do seu património imobiliário. A casa de Leiria foi vendida em $1894^{59}$. Utilizara a residência de grandes dimensões para transmitir uma imagem de poder e estatuto. Perdê-la significou lesar, publicamente, a sua posição entre os maiores da sociedade local. Algumas propriedades foram oferecidas, através do jornal, no ano seguinte $^{60}$. Tudo isto não foi suficiente para recuperar a liquidez financeira, pois em 1898 apresentou-se a receber $130 \$ 000$ réis, emprestados pelo Montepio de Nossa Senhora da Encarnação ${ }^{61}$. Foi afiançado pelos seus dois filhos e genro. 
Perdemos o contacto com José Joaquim Leitão até 1906. Decidira voltar a casar. Pela idade avançada, pela irregularidade da sua situação nos últimos anos e porque a noiva, D. Marcela Caiado, era senhora de alguma fortuna, justificou-se celebrar uma escritura antenupcial ${ }^{62}$. O seu prestígio já estava abalado, perante a opinião pública, como transparece dos atributos profissionais, fornecidos pelo notário. Deixara de ser "proprietário e negociante" para passar "a viver de sua agência". Passara também a uma situação pouco vulgar: vivia no Hotel Central, exactamente propriedade da sua noiva. D. Marcela era senhora sem pergaminhos. Viera para Leiria como exposta da Santa Casa da Misericórdia de Lisboa. Associara-se a Caetana da Conceição para explorar esta unidade hoteleira, sita na Travessa de Sant'Ana, onde ocupava um edifício, cuja extensão ficava compreendida entre as portas número 5 e 15. Era um local central, próximo da estrada que ligava Lisboa ao Porto. Aqui se deslocou o notário para redigir o contrato a celebrar entre José e Marcela, às dez da noite, de 3 de Setembro de 1906. Hora insólita, explicitada de forma intencional no documento? Talvez. $O$ nubente apresentava uma situação económica desastrosa, traduzida na informação de que "não possue actualmente bens alguns e por isso nenhuns leva para o casal" $"$.

Ao iniciar a sua actividade comercial, José Joaquim Leitão parecia ser o principal herdeiro da experiência legada pelos pais. Ao longo de quase trinta anos, investiu os lucros alcançados no comércio, na compra de propriedades rústicas e urbanas. Ser proprietário aliava-se, obrigatoriamente, ao mundo do negócio. Cumpria o percurso da burguesia urbana: senhora de uma fonte de receita fixa, tornava-se proprietária na periferia da cidade. José não teve sucesso. As lacunas da informação escondem os motivos de tão drástica viragem. Pertencer a família de prestígio local criava obrigações de conduta que, nem sempre, as conjunturas económicas permitiram concretizar. $O$ peso da crítica e do controlo social não deixavam de se manifestar. Daí a cobertura da noite e a escolha do espaço privado para tornar mais discreto o acto público que celebrou, ao preparar o segundo casamento.

O desenvolvimento da história de vida de José Joaquim Leitão demonstrou que, iniciado um processo de decadência económica, as elites criam barreiras para impedir que os indesejados se mantenham no seu seio. Marginaliza-os e retira-lhes o gosto pelo convívio social. Pede-lhes descrição.

Quando morre, em finais de 1911, o periódico local, de que o filho era director, prestou-lhe uma homenagem. Desaparecia, com 82 anos, o "antigo comerciante das praças de Leiria e Nazaré e o gerente do Hotel Central" ${ }^{\prime 64}$. Foi esta a forma encontrada para reabilitar a sua personalidade. 


\subsection{Luís Joaquim Leitão: o ignorado}

Foi o único homem, desta geração da família Leitão, que não esteve ligado ao comércio. Dos pais herdou, unicamente, uma propriedade no arrabalde. Não lhe transmitiram qualquer gosto pela actividade que desenvolveram $\mathrm{e}$ reproduziram nos seus outros três rapazes. Luís Joaquim Leitão esteve ligado à função pública, a partir de 1867, como Tesoureiro Geral do Distrito de Leiria $^{65}$. Enquanto o irmão José acumulou este cargo com as suas lides comerciais, Luís dedicou-se-lhe de forma exclusiva.

Tornou-se no primeiro elemento masculino de uma família de comerciantes a não cumprir a tradição. Por isso mesmo, foi ignorado pela sociedade leiriense.

\section{A SEGUNDA GERAÇÃO}

\subsection{Adolfo Augusto Leitão: a charneira}

Entre os elementos da segunda geração da família Leitão, Adolfo Augusto foi, sem dúvida, a figura mais brilhante.

Comerciante, presidente da Associação Comercial de Leiria, por vários anos, presidente do Grémio Recreativo, professor e, posteriormente, reitor do Liceu Nacional de Leiria foi cidadão de grande prestígio e respeitável representante dos Leitão.

Entre 1881 e 1913 foi sócio da casa Leitão \& Companhia. Esta alterou, por vezes, a sua composição societária, mas Adolfo Augusto acompanhou-a sempre, representando-a em actos públicos, acumulando o desempenho de outros cargos e funções.

Inicia-se como caixeiro da loja de Miguel Joaquim Leitão. A designação de caixeiro, para além de cobrir uma mobilidade de camadas da periferia da cidade, ou mesmo do mundo rural, pode também esconder "a situação de filhos de negociantes (portuenses), cujo início de carreira se fazia, por vezes, ao balcão do pai ou de um familiar" ${ }^{" 66}$. Em 1876, o seu patrão e tio propõe-lhe sociedade. Perdera a mulher havia pouco tempo e, "desejando descançar dos trabalhos e fadigas de sua laboriosa vida" ${ }^{\text {"67 }}$, procura parceiros para continuar na lida comercial, de forma aliviada. Junta ao dinheiro da filha Carolina, $6650 \$ 000$ réis, a indústria de Adolfo Augusto. Cedia o seu nome e o fundo que possuía em armazém, que ultrapassava dezassete contos de réis.

O experiente comerciante apostava em cheio na escolha do sobrinho, tanto mais que, no ano seguinte, Carolina e o marido afastaram-se da sociedade ${ }^{68}$. 
Tal como outros elementos da família, era homem interessado e atento às necessidades culturais e recreativas da Leiria. Iniciou-se no trabalho associativo, através do Grémio Recreativo Leiriense, de que foi vice-presidente, em $1880^{69}$. Aliás, era exactamente um grupo de jovens comerciantes, alguns ainda caixeiros, que liderava esta associação. Neste sector de actividade económica, Leiria encontrava os suportes do seu desenvolvimento. Vivia-se uma fase em que a cidade se revia na sua classe comercial. Alguns profissionais haviam já preparado o caminho para que os comerciantes atingissem, agora, um estatuto tão digno.

A geração mais nova encontrava nos estudos uma fonte de progredir, social e profissionalmente. Adolfo Augusto Leitão frequentou a Escola Comercial de Lisboa, onde adquiriu habilitações para leccionar francês e inglês no Liceu de Leiria $^{70}$. Em 1911, já em plena I República, foi nomeado reitor deste estabelecimento de ensino.

As profundas alterações políticas que o país viveu, com a implantação do novo regime, não afectaram o espaço social que, até então, havia conquistado. Pelo contrário. Continuava à frente da Associação Comercial de Leiria e adquiria, agora, esta posição, altamente prestigiante no panorama da educação, do funcionalismo e do estatuto social. Foi o garante da continuidade da posição, já anteriormente alcançada pela família Leitão.

\section{A TERCEIRA GERAÇÃO}

Adolfo Augusto Leitão transmitiu um conceituado nome de família aos seus filhos. Por aliança de casamento, ligara-se a uma outra importante família de comerciantes da praça leiriense, ao desposar D. Isaura de Almeida Teixeira, filha de José Jorge da Silva Teixeira, seu companheiro de direcção da Associação Comercial de Leiria. Alargava-se a qualidade destes laços de parentesco, através dos casamentos das suas filhas: Regina desposava, em 1908, o Dr. Fernando Baeta Neves, médico em Lisboa ${ }^{71}$, enquanto Maria Amélia, em 1917, se tornava esposa de um alferes de artilharia, António Fernando Gomes Pereira ${ }^{72}$.

A consolidação do lugar atingido na sociedade local foi reforçada através dos filhos. A terceira geração acomodou-se aos novos requisitos sociais. Adquiriu títulos académicos e integrou-se na política. 


\subsection{Miguel Teixeira Leitão: o herdeiro da tradição}

O escolhido para continuar a tradição da família, na actividade comercial, foi Miguel. A sua entrada foi totalmente preparada pelo pai, quando o integrou na sociedade Leitão \& Companhia, em 31 de Julho de $1913^{73}$. Não esqueçamos esta prática de transmissão de saberes, dentro da classe dos comerciantes, também verificada entre famílias portuenses ${ }^{74}$. A casa especializara-se em fazendas de lã e de algodão. Contava com uma sucursal em Ourém. Também possuía um armazém de tabacos. Valia, então, oitenta e quatro contos. Era um grande estabelecimento, não só em prestígio e liquidez, mas também nas suas dimensões. Ocupava as portas número 6 a 12, na Rua do Comércio.

Lentamente, o pai, sócio maioritário, foi transferindo para o filho a representatividade da firma em actos públicos.

Miguel Teixeira Leitão foi um fiel depositário da tradição. $\mathrm{O}$ estabelecimento chegou aos nossos dias, depois de ter atravessado conjunturas económicas bastante desfavoráveis. Aliás, hoje encontra-se a viver a pior delas, na opinião do seu actual sócio gerente. Já não tem o apelido Leitão ${ }^{75}$.

\subsection{Adolfo Teixeira Leitão: o político}

Concluiu o curso de Direito, em Coimbra, em 1911, como noticiou um dos jornais da cidade ${ }^{76}$. A família revia-se neste seu doutor. O director do jornal não lhe poupou referências elogiosas.

Pertencente a uma geração criada nos anos de derrocada monárquica, aderiu à causa republicana. Foi uma das personalidades que, da varanda dos Paços do Concelho, falou à população, aquando da proclamação do primeiro Presidente da República ${ }^{77}$. Homem activo e de cultura superior, integrou a comissão que preparou as comemorações do 5 de Outubro de 1911 (primeiro aniversário da implantação da República). Progrediu na política local, já que, em 20 de Dezembro de 1913, foi eleito presidente da Comissão Municipal Administrativa $^{78}$.

Não descurou a sua vida profissional. Assim, em 1915, foram frequentes os anúncios em que publicitou o seu escritório de advocacia, em Leiria. Ligado à função pública, foi conservador do Registo Civil, na mesma cidade ${ }^{79}$. Ainda em 1915, demonstrou que a universidade era compatível com a aprendizagem feita em família. Formou uma sociedade para explorar uma leitaria, na Praça Rodrigues Lobo, dando origem à firma Leitão \& Estrela ${ }^{80}$. Tornava-se sócio capitalista, pois o trabalho (ou indústria) era todo entregue ao seu parceiro social $^{81}$. 


\subsection{Acácio Teixeira Leitão: o poeta}

Faltava um homem de letras na família Leitão. Acácio ocupou este espaço. Tal como seu irmão Adolfo, concluiu o curso de Direito, em Coimbra. Não abriu escritório em Leiria, mas desempenhou cargos na magistratura. Ocupou o lugar de Juiz do Tribunal do Trabalho, nas Comarcas de Vimioso e de Alcobaça.

Para além da sua profissão, dedicou-se à poesia, actividade com que foi galardoado, ao ser atribuído o seu nome a uma rua da cidade, em 1973. Pode ler-se o atributo concedido: "poeta leiriense". Mais do que a sua qualidade literária, homenageou-se o membro de uma família ilustre, que participou activamente na construção de uma cidade mais moderna.

\section{CONCLUSÃO}

Damos por concluída, por agora, a investigação levada a cabo sobre uma família que, a nível local, dominou instâncias do poder económico e social. As dimensões do protagonismo que atingiu tornaram-na presente em quase todos os níveis do quotidiano leiriense. Os Leitão encabeçaram movimentos cívicos, culturais e políticos. Construíram um alargado espaço de intervenção e de liderança. Não desprezaram o poder decorrente das alianças estabelecidas por casamento.

Com base num sector da vida económica, a família Leitão criou um nome respeitado por todos ${ }^{82}$. Os próprios empregados que passaram pelas suas casas comerciais gozaram de um estatuto que os diferenciava entre os seus colegas de profissão ${ }^{83}$. Diferentes gerações alimentaram a posição e o estatuto a que o comércio lhes dera acesso. Mas não foram só as actividades comerciais que mantiveram este grupo no convívio da mais alta sociedade leiriense. Promoveram a identidade da burguesia local por comportamentos que passaram pela posse de habitação de férias, pela preservação de rituais de sociabilidade em ambientes restritivos, pela adopção de estratégias de ligação aos mais notáveis da cidade.

Foi permitido aos seus membros que enveredassem por cargos de responsabilidade no aparelho da administração pública. Exerceram controlo de informação, de forma mais ou menos evidente, ao tornarem-se elementos inatacáveis da sociedade local ou ao dirigirem o seu próprio jornal. Promoveram a aquisição de títulos académicos entre as gerações mais novas. Educaram os seus filhos para que continuassem a sua actividade, mas deram-lhes, também, uma formação superior, que acrescentasse prestígio ao indivíduo e ao grupo familiar ${ }^{84}$. Deixaram um nome entre os homens de letras, 
a nível local. Ficou demonstrado que também a família burguesa da província se apresentava como um espaço que admitia trajectórias individuais aos seus membros, segundo o contexto socio-histórico, como verificou Gaspar Pereira (1996: 153), na mesma época, para o Porto.

Por tudo isto, e pela sua presença permanente na vida de Leiria, pode dizer-se que a família Leitão interveio na vida da cidade, por mais de sessenta anos. A transmissão de uma prática comercial, entre gerações, demonstrou não enveredar por modelos de comportamento repetitivos, que obedecessem a estereótipos criados pela primeira geração. Os mais jovens, não tendo criado rupturas na correia de transmissão dos saberes, adaptaram-se à modernidade $\mathrm{e}$ valorizaram a mudança.

Nem todos os seus membros brilharam com a mesma intensidade. Mas, como demonstra Sonsoles Gómez Cabornero (1999: 153), a propósito de uma importante família de Zamora, para ingressar no grupo da burguesia "não é suficiente possuir prósperos negócios e uma renda elevada, mas é necessário manifestar determinados hábitos que identificam esta classe social". Até ao momento da ruptura, tinham-se comportado como iguais. $O$ silêncio, que sobre eles pesou, mostrava que se tinham quebrado alguns laços entre a sociedade e os Leitão menos afortunados. Sobre estes não deixaram de se mobilizar estratégias de reabilitação que esconderam a sua marginalização com o protagonismo de outros membros da família. Em causa última estava a limpidez do nome.

A forma como evoluiu a actividade económica da família Leitão proporcionou a análise do sector comercial, a nível local. A cidade, de meados do século XIX aos primeiros anos da I República, foi um espaço aberto a toda a inovação. As novas estratégias de implantação no mercado conviveram com algumas práticas bastante tradicionais em adquirir símbolos de riqueza e de poder. A necessidade de formar quadros profissionais apontava para 0 objectivo de alcançar qualidade. A aprendizagem, proporcionada exclusivamente pela experiência, começava a ser posta em dúvida. A diferença do serviço prestado aos clientes passava, também, pela qualificação académica da classe dos comerciantes.

Tudo isto integrou a história da família Leitão. Sabemos que os grupos sociais apresentam dinâmicas lentas e, por vezes, imperceptíveis ao actuar no sentido da mudança. Percorrem uma linha evolutiva coesa e homogénea onde, dificilmente, se identificam os pontos que provocaram pequenas fracturas. Este princípio foi muito evidente, através desta família. Mas ela também mostrou que 50-60 anos é o tempo em que ocorrem alterações comportamentais evidentes, mesmo ao nível das mentalidades.

Foi nossa intenção contrariar um aviso deixado por Jean Poirier (1995: 85): "a história de vida não pode ser ... um pretexto e um desvio para 
demonstrações insidiosas e para generalizações sem verdadeiro fundamento". Esperamos tê-lo conseguido.

\section{NOTAS}

${ }^{1}$ Cfr. Hélder A. Fonseca, "As elites económicas alentejanas, 1850-1870: anatomia social e empresarial”, Análise Social, vol. XXXI, n 136-137, 1996, p. 712.

${ }^{2}$ G. Bandelier, ao prefaciar o trabalho de F. Ferrarotti, Histoire et Histoires de Vie. La méthode biographique dans les sciences sociales, aponta o percurso histórico do método da história de vida, relacionado com a área sociológica e, também, antropológica. O quadro de argumentação que apresenta não deixa de ser aplicável ao campo da História.

${ }^{3}$ Noutro trabalho de maior fôlego, propomo-nos analisar, em detalhe, a evolução da fortuna de alguns membros desta família, através das sociedades comerciais que foram constituindo entre 1853 e 1913.

4 Biblioteca Pública e Arquivo Distrital de Leiria (BPADL)-Registo Paroquial, freguesia de Leiria, ano de 1850.

${ }^{5}$ Idem, Livro Notarial do Tabelião André Avelino Coelho do Vale, fls. 1-4, de 16 de Dezembro de 1853.

${ }^{6}$ Será redigida, de imediato, uma escritura de arrendamento, por 20 anos, com a renda anual de $30 \$ 000$ réis. Livro notarial 11D-59, de 16 de Dezembro de 1853.

${ }^{7}$ BPADL- Livro notarial n5, fl. 38v-39, de 4 de Novembro de 1853.

${ }^{8}$ João Cabral, Anais do Município de Leiria., vol. I, p.326.

${ }^{9}$ BPADL, Livro $n^{\circ} 7$, fl. 79v, de 8 de Agosto de 1857.

${ }^{10} O$ Leiriense, $\mathrm{n}^{\circ} 7$, de 22 de Julho de 1854.

"Idem, $\mathrm{n}^{\circ} 52$, de 30 de Dezembro de 1854

${ }^{12}$ Idem, $\mathrm{n}^{\circ} 93$, de 23 de Maio de 1855.

${ }^{13}$ Idem, $\mathrm{n}^{\circ} 131$, de 6 de Outubro de 1855.

${ }^{14}$ Idem, $\mathrm{n}^{\circ} 118$, de 22 de Agosto de 1855.

${ }^{15}$ Aviso, datado de 1 de Outubro de 1854.

${ }^{16}$ O Leiriense, $\mathrm{n}^{\circ} 153$, de 25 de Dezembro de 1855.

${ }^{17}$ Idem, $\mathbf{n}^{\circ} 128$, de 26 de Setembro de 1855.

${ }^{18}$ Por exemplo, vide contratos celebrados em 1857. BPADL- livro $\mathrm{n}^{\circ} 7$, fls. $62 \mathrm{v}-63 \mathrm{v}$; $79 \mathrm{v}$.

${ }^{19}$ Idem, livro ${ }^{\circ} 3$, fls. $74 \mathrm{v}-75$, de 17 de Janeiro de 1851.

${ }^{20}$ Desconhecemos a data de criação. A alusão que lhe foi feita, em 1878, dizia apenas: “que já tem há muitos annos". Idem, livro no 35, fl. 9-9v, escritura de 29 de Julho de 1878.

${ }^{21}$ Ibidem.

${ }^{22}$ Vide, sobre o tema, A. de Castro, "Tabaco", Diccionário de História de Portugal. Também, Maria Filomena Mónica, “Negócios e Política: os tabacos (1800-1890)", Análise Social, vol. XII, p.461-479. 
${ }^{23}$ BPADL-escritura de 22 de Setembro de 1873.

${ }^{24}$ Idem - escritura de partilhas, feita por morte de Rosa Viterbo Leitão, em 20 de Outubro de 1876. Tab. Carlos Rufino C Vale, p. 71-72.

${ }^{25}$ Idem.

${ }^{26}$ Idem, livro ${ }^{\circ} 11$ D-76, fl. $21 \mathrm{v}$.

${ }^{27}$ Idem, livro $n^{\circ} 31$, fls. 95v-96; 96v-97; 97v-98. Escrituras datadas de 4 de Abril de 1877.

${ }^{28} \mathrm{O}$ teor do documento foi transcrito na escritura de partilha supra referida.

${ }^{29}$ BPADL-, Livro ${ }^{\circ} 7$, fl. 32v, de 1 de Março de 1860.

${ }^{30}$ Idem, Livro $\mathrm{n}^{\circ} 10$, fls. $90 \mathrm{v}$, de 31 de Outubro de 1864.

${ }^{31}$ Idem, Livro notarial 3, fls. 86-87, escritura de 18 de Março de 1851.

${ }^{32} O$ Leiriense, $n^{\circ} 51$ de 23 de Dezembro de 1854.

${ }^{33}$ Ibidem.

${ }^{34}$ Sobre o exercício do poder das elites, através destas iniciativas, vide S. Gómez Cabornero (1999), Familia, Fortuna y Poder, Salamanca.

${ }^{35}$ O Districto de Leiria, de 14 de Setembro de 1907.

${ }^{36}$ Este Teatro será destruído nos anos 50, deste século, por não apresentar condiçס̃es de conforto e de segurança, porque era totalmente construído em madeira. $O$ diferendo mantido entre a Câmara Municipal e a Associação do Teatro D. Maria Pia só viria a ser solucionado em 1966, aquando da inauguração do novo teatro municipal.

${ }^{37}$ BPADL- Livro notarial $n^{\circ} 41$, fls. 8-9, de 15 de Novembro de 1880.

${ }^{38} O$ Leiriense, $\mathrm{n}^{\circ} 30$, de 11 de Outubro de 1854.

${ }^{39}$ Idem, $\mathrm{n}^{\circ} 154$, de 29 de Dezembro de 1855: anuncia que tem à venda, na sua loja, $O$ Novo Diccionário Portátil Portuguez, em dois volumes

${ }^{40}$ BPADL - Livro notarial n ${ }^{\circ} 11 \mathrm{E}-7$, fl. 34, de 1 de Julho de 1880.

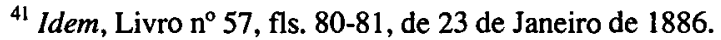

${ }^{42}$ Idem, Livro $\mathrm{n}^{\circ}$ 10C-11, fls. 41-42, de 9 de Fevereiro de 1894.

${ }^{43}$ Idem, Livro 11E-19, f1. 18, de 21 de Janeiro de 1893.

${ }^{44}$ Idem, Livro 10D-16, fl. 48, de 7 de Março de 1913.

${ }^{45} \mathrm{Idem}$, Livro ${ }^{\circ}$ 10I-36, fl. 39, de 17 de Novembro de 1904.

${ }^{46}$ Idem, Livro $\mathrm{n}^{\circ} 5$, fls. 38v-39, de 4 de Novembro de 1853.

${ }^{47} O$ Leiriense, $\mathrm{n}^{\circ} 27$, de 2 de Maio de 1854.

${ }^{48}$ BPADL - Livros $n^{\circ} 10^{A}-6,10-A-7$ e $10^{A}-37$, fls.55,61v e $78 v-79$, respectivamente. Anos de 1867 e 1879.

${ }^{49} \mathrm{Idem}$, Livros $\mathrm{n}^{\circ} 33$ e $11 \mathrm{E}-6$, fls. $89 \mathrm{v}$ e 2, relativas aos anos de 1876 e 1878.

${ }^{50}$ Idem, Livro $\mathrm{n}^{\circ} 10^{\mathrm{A}}-16$, fl. $78 \mathrm{v}-79$. Trata-se de um acto de hipoteca, de uma caução que necessita prestar, em 1869.

${ }^{51}$ Idem, Livro 10C-13, fl. 121-122, de 21 de Dezembro de 1894. Era uma escritura de venda. 
${ }^{52}$ Idem, Livro 11E-A, fl. 48. dado transmitido em escritura de caução, em 14 De Abril de 1880. $O$ investimento feito numa residência de grande dimensão prendia-se, segundo a opinião de Gaspar Martins, sobre comportamentos de famílias portuenses, com o elevado número de filhos e com o número de empregados domésticos que admitiam (Famílias portuenses na viragem do século, 1880-1910, p. 146-152). Entre a família Leitão, pensamos tratar-se de um evidente sinal exterior de riqueza, mais do que resposta a reais necessidades, decorrentes da quantidade dos residentes.

${ }^{53}$ BPADL-Livro 10A-16, fl. 78v-79. Escritura de caução, de 30 de Dezembro de 1869.

${ }^{54}$ Idem, Livro $\mathrm{n}^{\circ} 35$, fl. 52v-53v, de 30 de Outubro de 1878.

${ }^{55}$ Cfr. $O$ Radical, de 28 de Dezembro de 1911 , em notícia composta sobre a sua figura, quando morreu, aos 82 anos.

${ }^{56}$ BPADL - Livro 11E-6, fl. 48.

${ }^{57}$ Idem, Livro 11E-7, fl. 34, de 1 de Julho de 1880.

${ }^{58}$ Idem, Livro no 10H-30, fls. 59v-63, de 11 de Março de 1885.

${ }^{59}$ Idem, Livro $\mathrm{n}^{\circ} 10 \mathrm{C}-13$, fls. 121-122.

${ }^{60}$ O Leiriense, $\mathrm{n}^{\circ} 678$, de 23 de Março de 1895 . O anúncio manteve-se por mais sete semanas.

${ }^{61}$ BPADL-Livro $n^{\circ} 11 \mathrm{E}-29$, fl. 23, de 5 de Agosto de 1898.

${ }^{62}$ Idem, Livro $\mathrm{n}^{\circ} 11 \mathrm{E}-51$, fl. $1 \mathrm{v}$, de 3 de Setembro de 1906.

${ }^{63}$ Idem, Livro $\mathrm{n}^{\circ} 11 \mathrm{E}-51, \mathrm{fl} .1 \mathrm{v}$.

${ }^{64} O$ Radical, de 28 de Dezembro de 1911.

${ }^{65}$ BPADL - Livro $\mathrm{n}^{\circ} 10 \mathrm{~A}-8$, fl. 18v, de 10 de Julho de 1867.

${ }^{66}$ Cfr. Gaspar M. Pereira, op. cit., p.168.

${ }^{67}$ BPADL - Livro $n^{\circ} 1 \mathrm{H}-10$, notariado de Alcobaça, fl. 120, de 2 de Dezembro de 1876.

${ }^{68}$ Idem, Livro $\mathrm{n}^{\circ} 33$, fl. $18 \mathrm{v}$, de 17 de Dezembro.

${ }^{69}$ Idem, Livro $\mathrm{n}^{\circ} 41$, fls. $49 \mathrm{v}-50$, de 17 de Janeiro de 1880 . Escritura de arrendamento de sede, em edificio do Visconde de S. Sebastião.

${ }^{70}$ Os Anuários do Liceu Nacional de Leiria apresentavam-no entre os seus professores efectivos, a partir do ano lectivo de 1898/1899.

${ }^{71}$ Cfr. Echos do Liz, de 11 de Dezembro de 1908.

${ }^{72}$ Cfr. Jornal de Leiria, de 18 de Fevereiro de 1917.

${ }^{73}$ BPADL - Livro 10I-70, fl.26.

${ }^{74}$ Caso da família Mendonça. Cfr. Gaspar Pereira, op. cit., p.164-171.

${ }^{75}$ Trata-se do Sr. Faria, que nos cedeu um tempo para que o entrevistássemos, em Março de 1997.

${ }^{76}$ O Radical, de 27 de Julho de 1911.

${ }^{77}$ Idem, de 24 de Agosto de 1911.

${ }^{78}$ Leiria Ilustrada, ${ }^{\circ} 419$, de 3 de Janeiro de 1914.

${ }^{79}$ Cfr. Jornal de Leiria, de 18 de Fevereiro de 1917. 
${ }^{80}$ Começou por receber o estabelecimento por trespasse, pelo qual pagou 902\$00: cfr. Livro $\mathrm{n}^{\mathrm{0}} 11 \mathrm{~F}-9$, fls. $45 \mathrm{v}$.

${ }^{81}$ A leitaria foi registada no Registo Comercial, Livro E, em 4 de Outubro de 1915.

82 Dentro da praça leiriense, analisada pela óptica dos inspectores do Banco de Portugal, em serviço na agência de Leiria, a firma Leitão \& $C^{\circ}$ era qualificada, em 1904, como "um bom armazém de muitos artigos". O seu sócio maioritário, Adolfo Augusto Leitão, era possuidor, segundo a mesma fonte, de fortuna situada entre os 60 e 70 contos de réis (AHBP - Relatório da Inspeç̧ão feito à agência do Banco de Portugal em Leiria, datado de 21 de Junho de 1904). Nesse mesmo ano, a mesma instituição bancária considerou-a como "a primeira casa comercial da praça".

83 A imprensa local não deixava de registar a importância atribuída, social e profissionalmente, aos empregados da família Leitão. Assim aconteceu em 1906, aquando do casamento de José Maria Baptista "digno e honrado empregado na casa comercial Leitão \& Ca . (Leiria Ilustrada, de 25 de Outubro de 1906). Repetir-se-ia a mesma deferência, já em 1917, quando José da Rocha Barbosa, "empregado da importante firma Leitão \& Ca.", pediu a sua noiva em casamento. Por sinal, esta era a "gentil filha" de um benquisto negociante da cidade (Jornal de Leiria, de 18 de Fevereiro de 1917).

${ }^{84}$ Sobre a educação dos filhos da classe média oitocentista, vide Pamela Pilbeam, The middle classes in Europe, 1789-1914, Macmillan, London, 1990, p.173-209; 294-302. Distingue, por exemplo, a carreira de leis, seguida por este grupo.

\section{FONTES E BIBLIOGRAFIA}

\section{Fontes:}

\section{REGISTO COMERCIAL DE LEIRIA (RCL):}

Registo Comercial e Industrial de Leiria: registo de sociedades (1897-1914).

\section{ASSOCIAÇÃO COMERCIAL E INDUSTRIAL DE LEIRIA (ACL):}

Actas da Associação Comercial de Leiria.

\section{BIBLIOTECA PÚBLICA E ARQUIVO DISTRITAL DE LEIRIA (BPADL):}

Livros notariais (Notariados de: Leiria, Alcobaça): 1836-1915. Livros de Registos Paroquiais.

\section{Publicações e periódicos:}

Anuário Comercial de Portugal, Empresa Nacional de Publicidade, Lisboa, 1895-1914. Anuario do Liceu Nacional de Leiria.

A Capa (Leiria: 1911-1912) 
Correspondencia de Leiria (Leiria: 1874-1877)

Echos do Liz (Leiria: 1907-1911)

Leiria llustrada (Leiria: 1905-1916)

Liz (Leiria: 1913)

Liz e Lena (Leiria: 1890-1902)

O Distrito de Leiria (Leiria: 1899-1910)

O Jornal de Leiria (1911-1917)

O Leiriense (Leiria: 1854-1867; 1898-1899; 1904; 1907-1908)

O Liz (Leiria: 1856-1857)

O Mensageiro (Leiria: 1914-1916)

O Radical (Leiria: 1911-1916)

O Rebelde (Leiria: 1910-1911)

\section{Bibliografia:}

CABRAL, João (1993), Anais do Município de Leiria, 2 volumes, Câmara Municipal de Leiria, Leiria.

DAUMARD, Adeline (1992), Os Burgueses e a Burguesia na França, Livraria Martins Afonso, S. Paulo.

EISENSTADT, S. (1991), A dinâmica das civilizações. Tradição e modernidade, Edições Cosmos, Lisboa.

FERRAROTTI, Franco (1990), Histoire et Histoires de Vie. La méthode biographique dans les sciences sociales, Méridiens Klinckieck, Paris.

FONSECA, Hélder Adegar (1996), O Alentejo no Século XIX: economia e atitudes económicas, Imprensa Nacional, Lisboa.

GÓMEZ CABONERO, Sonsoles (1999), Familia, Fortuna y Poder. La saga política de los Rodriguez en la restauración zamorana, Instituto de Estudios Zamoranos, Salamanca.

MARGARIDO, Ana Paula (1988), Leiria, história e morfologia urbana, Edição Câmara Municipal de Leiria, Leiria.

MARTINS, Conceição Andrade (1992), "Opções económicas e influência política de uma família burguesa oitocentista: o caso de S. Romão e José Maria dos Santos", Análise Social, XXVII, n 116-117, p. 367-404 .

MENDES, J. M. Amado (1992), "O contributo da biografia para o estudo das élites locais: alguns exemplos", Análise Social, XXVII, n' 116-117, pp. 357-365.

PEREIRA, Gaspar Martins (1995), Familias portuenses na viragem do século (1880-1910), "Biblioteca das Ciências do Homem", Edições Afrontamento, Porto.

PILBEAM, Pamela (1990), The middle classes in Europe, 1789-1914. France, Germany, Italy and Russia, Macmillan, London.

POIRIER, Jean et al. (1995), Histórias de Vida. Teoria e prática, Celta Editora, Oeiras. 